7ap. Psychol. Research

No. 9, 1960

\title{
FIGURE-GROUND REVERSALS UNDER SUCGESSIVELY REPEATED OBSERVATIONS
}

\author{
SHUKO TORII
}

\author{
University of Tokyo
}

The apparent alternations of figures (figure-ground reversals) which occur under continuous observation of an ambiguous pattern such as Fig. 1 have been studied in relation to the properties of a stimulus pattern $(\mathbf{4}, \mathbf{5}, \mathbf{7}$, $10,11,13,14,15,17)$. In the present paper an attempt is made to determine whether the rate of reversals is affected by successively repeated observations with fixed intervals (repeated observations).

Köhler (8) found that by repeated observations with fixed intervals (1 min.), the reversals followed each other more and more quickly; that is, the rate of reversals increased gradually and continuously as the observation went on. Philip and Fisichelli (16), Fisichelli (3) and Brown (1), using different dynamic ambiguous figures, reported that similar results were obtained by continuous observation without any interval ( $1 \mathrm{~min}$. and $4 \mathrm{~min}$. respectively).

Obonai (11), however, reported that the reversals tended to decrease under continuous observation of the pattern such as Fig. 1 (3 min.). Bruner, Postman and Mosteller (2) observed a similar tendency for prolonged continuous observation (10 min.) of Schröder's stair.

On the other hand, Guilford and Braly (6) found no change in the rate of reversals by repeated observations of the Necker cube with 3 min. intervals. The author previously reported a very slight decreasing tendency in the rate of reversals when the observation was prolonged for $12 \mathrm{~min}$. But the above ten- dency was not statistically significant, and it was concluded that no significant change existed in the rate of reversals. Künnapas (10) reported a similar result.

Since Obonai's data pointed to the fact that, when the observation was interrupted by a certain length of interval, the rate of reversals was accelerated, it would be unreasonable to generalize as Köhler did, that is, to explain the change of the rate of reversals under continuous observation only by data drawn from the result of observations repeatedly conducted with intervals. Therefore, it would be necessary to examine whether any change in the rate of reversals is to be found by repeated observation with intervals of various length.

\section{General Method}

\section{Stimulus material}

The reversible figure-ground patterns used are shown as Fig. 1. In each pattern the circle (diameter: 5 or $10 \mathrm{~cm}$ ) was divided into six sectors by black lines drawn with India ink or by gray papers differing in brightness. Three of these sectors was called " $\alpha$ ", and the remaining three " $\beta$ ". In the case of Fig. 1-1, the pattern was drawn in the center of a white card which was $20 \times 30 \mathrm{~cm}$, and in the case of Fig. 1-2, Fig. 1-3, Fig. 1-4, the pattem was placed on the center of a middle gray card (reflectance: $17 \%$ ) which was $20 \times 20$ $\mathrm{cm}$.

\section{Apparatus}

A supporting board for the stimulus card 

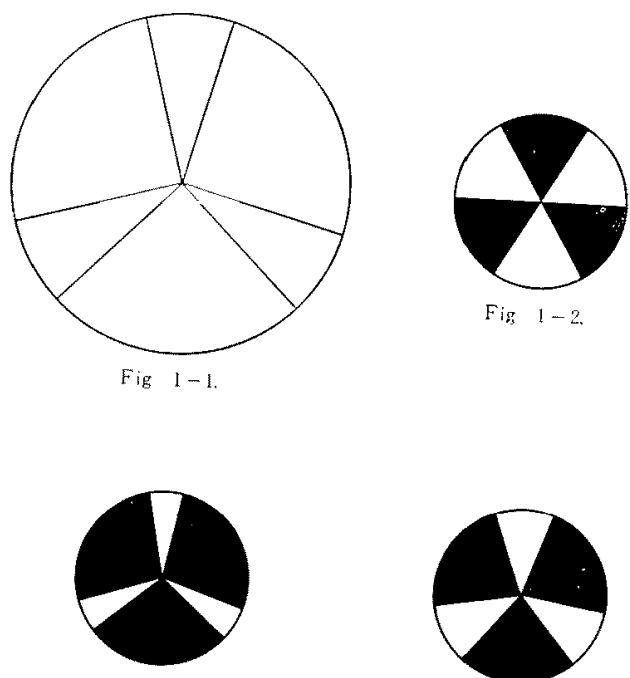

Fig $\quad 1-3$

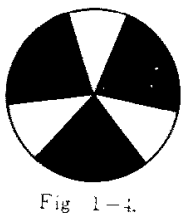

Fig. 1. Stimulus patterns used in Experiments I-VI.

was placed in front of the observer $(O)$. The board was covered with white sheet in the case of Fig. 1-1, and middle gray paper (reflectance: $17 \%$ ) in the case of Fig. 1-2, Fig. 1-3, Fig. 1-4. The illuminance was 4 footcandles. The distance between the $O$ 's eyes and the stimulus was $115 \mathrm{~cm}$. A chinrest was used.

Two telegraph keys were placed in front of $O$. They were connected to the markers of a chronograph so as to mark the duration in which " $\alpha$ " (or " $\beta$ ") was seen as a figure.

\section{Procedure}

One assistant and six students of psychology. five males and two females served as observers in the experiments. Three had normal vision and the rest wore corrective glasses. All were experienced in the observation of the reversible pattern.

$O$ was instructed as follows: "You are to observe a reversible pattern. Now the pattern is covered with white paper (or middle gray paper in Exp. III, IV, V). When the experimenter says 'Ready', look at the center of this paper and with the signal ' Now', the paper will be removed. Then look at the center of the pattern, and keep this fixation throughout the observation. Press the right-hand (left-hand) key as soon as you see ' $\alpha$ ' (' $\beta$ ') as a figure and keep pressing while the figure stays. Do not press the keys when you see no figure or you see an undefined figure." There were additional instructions that differed from experiment to experiment. Observations were made binocularly.

Observations were made for a fixcd timc, in which a given number of appearance of figures were reported by $O$ in the case of Exp. I, II, III, and V, while in the case of Exp, IV and VI the observation time was fixed by the experimenter $(E)$. That is to say, in the former case the observation times in which a given number of figures were seen, were measured, and in the latter case the number of appearance of figures was measured for a fixed time. At the termination of the observation time, $E$ said "all right", then the stimulus was covered again with the above-mentioned white paper (or gray paper). In the case of repeated observation (Exp. I, II, III, $\mathrm{IV}, \mathrm{V})$, after the interval, $O$ was instructed to fixate on center of the white paper (gray paper) and the next observation followed. In Exp. VI, the observations were continued without any intervals.

\section{Measure}

The first duration in which " $\alpha$ " (or " $\beta$ ") was seen is indicated as $t_{\alpha 1}$ (or $t_{\beta 1}$ ); the second as $t_{\alpha 2}$ (or $t_{\beta 2}$ ), and so forth. The undefined phase in which neither figure was seen is denoted $t_{\varepsilon}$. Definition related to the rate of reversals are as follows: (a) $T$ is defined as the total time in which the stimulus is presented to the $O$. Let $T_{a}=t_{\alpha 1}+t_{\alpha 2} \ldots, T_{\beta}-t_{\beta 1}+t_{\beta 2} \ldots$ and the total of the undefined phases is denoted $T_{s}$, then $T=T_{a}+T_{\beta}+T_{\varepsilon}$. Therefore, when the number of reversals is fixed, i.e. $T$ is the dependent variable, the rate of reversals is high, when $T$ is short, and vice versa, so 
long as $T_{c}$ remains negligible. The successive occurrence of either $\alpha$ or $\beta$ is defined as a reversal i.e., $\alpha-\alpha, \alpha-\beta, \alpha-\beta$ or $\beta-\beta$. (b) When observation time is constant as in Exp. IV and VI, the average number of appearances $\left(\mathcal{N}=\left(n_{\alpha}+n_{\beta}\right) / 2\right)$ is the measure of the rate of reversals, $n_{\alpha}$ (or $n_{\beta}$ ) being the number of times " $\alpha$ " (or " $\beta$ ") appear as figures. If $\mathcal{N}$ is proportionately large, the rate of reversals is high, and zice versa. (c) The average duration of the figure $\left(t_{\alpha}, t_{\beta}\right)$ is calculated from the following equation: $t_{\alpha}=T_{\alpha} / n_{\alpha}, \quad t_{\beta}=T_{\beta} / n_{\hat{\beta}}$. Therefore, if $t_{\alpha}\left(t_{\hat{\beta}}\right)$ is short, and $T_{\varepsilon}$ is negligible, the rate of reversals is high and vice versa.

\section{I}

According to Köhler $(\mathbf{8})$, Köhler and Wallach (9), the alternation of figures can be explained in following way: (a) The prolonged occurrence of a figure produces an effect* which opposes its further existence. (b) When the effect reaches a certain critical degree reversal of the figure occurs.

Köhler also states: "this effect seems to persist beyond the time during which the figure process actually occurs " $(\mathbf{8}$, p. 72). This leads to the conclusion that by prolonged observation the effect will be accumulated gradually and continuously and the time in which the effect reaches a critical degree will be shortened, the duration of a figure will be shortened, and the rate of reversals will be accelerated.

If he is right in assuming that "it (effect) may not completely disappear in a minute or more" (8, p. 72), under repeated observations with intervals of a minute or more the rate of reversals will be accelerated. And the shorter the intervals are, the accumulation of the effect should be stronger.

* For the present purpose it might be admissible to disregard the physiological hypothesis suggested by Köhler.

\section{EXPERIMENT I}

\section{Method}

The stimulus was a circle (diameter: 10 $\mathrm{cm}$, visual angle: 5 , shown in Fig. 1-1, divided into six sectors by black lines (width: $0.5 \mathrm{~mm}$, visual angle: $15^{\prime}$ ). O was instructed to retain the figure seen at the moment as long as possible and not to try to change to another. The total duration $(T)$, in which 10 figures were observed was recorded, and this was repeated six times with fixed intervals. The intervals were $10,60,120$, and 0 seconds (60 figures were observed without any interval). Experiments were performed with one condition of interval on a given day. Four $O$ s took part in this experiment.

\section{Results}

One $O$ showed a slight tendency of a lengthening in $T$ under $0 \mathrm{sec}$. and a shortening under $10 \mathrm{sec}$. as the observation proceeded. Table 1 shows the average $T$ of four $O_{\mathrm{s}}$ for 6 repetitions under 4 different intervals. The results indicate, as a whole, that there is no significant change in $T$ as a function of successive observations. Neither $T_{a}$ and $T_{\beta}$ nor $T_{\epsilon}$ showed any decreasing or increasing tendency (data not shown). Therefore, as far as the results of this experiment are concerned, it is difficult to conclude that the rate of reversals is gradually accelerated.

Next, in order to examine the effect of the intervals on $T$, the four averaged $T_{\mathrm{s}}$ of 6 repeated observations are compared. As shown in Table 1, the averaged $T$ for 10 and $60 \mathrm{sec}$. interval is shorter than that for $0 \mathrm{sec}$. The average $T$ for a $120 \mathrm{sec}$. interval is not different from that of $0 \mathrm{sec}$.

To examine precisely the influence of interval on the rate of reversals, the first duration of $\alpha$ and $\beta$ for each of the six successive observations, on which the influence of interval may be most effec- 
Table 1

The total time $(T)$

\begin{tabular}{c|cccccc|c}
\hline Intervals $\downarrow \begin{array}{c}\text { Order of mea- } \\
\text { surement } \rightarrow\end{array}$ & 1 & 2 & 3 & 4 & 5 & 6 & AV \\
\hline 0 sec. & 57.3 & 62.0 & 63.7 & 57.3 & 63.0 & 53.0 & 59.4 \\
10 sec. & 53.7 & 43.7 & 45.7 & 46.7 & 37.3 & 36.3 & 43.9 \\
$60 \mathrm{sec}$. & 52.7 & 47.3 & 48.7 & 36.0 & 39.3 & 46.0 & 45.0 \\
$120 \mathrm{sec}$. & 58.0 & 48.7 & 46.0 & 60.0 & 72.0 & 71.7 & $\begin{array}{c}59.4 \\
(\text { sec.) }\end{array}$
\end{tabular}

Table 2

First duration of figure $\left(t_{\alpha_{1}}+t_{\beta_{1}}\right)$

\begin{tabular}{c|cccc}
\hline Intervals $\rightarrow$ & 0 sec. & $10 \mathrm{sec}$. & $60 \mathrm{sec}$. & $120 \mathrm{sec}$. \\
\hline$t_{\alpha}+t_{\beta}$ & 9.3 & 8.3 & 7.0 & $\begin{array}{c}6.6 \\
(\mathrm{sec} .)\end{array}$
\end{tabular}

tive, was adopted as a measure. Table 2 indicates that the longer the intervals, the shorter the first duration of $\alpha$ and $\beta$. From this result, it would be reasonable to assume that the interval effectively increases the rate of reversals. This assumption, however, needs closer examination on the following points : First, is the $T$ adopted here the same as the one used in Köhler's experiment? Second, is the stimulus material used here adequate? Experiments II and III were designed to clarify the above problem.

\section{EXPERIMENT II}

\section{Method}

In Exp. I $T$ was one in which 10 figures were seen, namely $n_{\alpha}+n_{\beta}=10$. Due to the random alternations of figures, however, $n_{a}$ was not always equal to $n_{\beta}$ (see difinition of reversal). In most cases $n_{\alpha}$ was larger than $n_{\beta}$ in Exp. I. Hence $n_{\alpha} \geq 5$ and $n_{\beta} \leq 5$. Therefore, $T$ in Exp. I might not be necessarily the same as " the time for 5 complete cycles"* in Köhler's experiment. Suppose

* Köhler annotated "the fifth cycle is completed when the first figure appears for the sixth time, including its appearance in the beginning." (See 8, p. 70)
Table 3

The total time $(T)$

\begin{tabular}{c|cc}
\hline Intervals $\rightarrow$ & $10 \mathrm{sec}$. & $60 \mathrm{sec}$. \\
\hline$T$ & 57.3 & $\begin{array}{c}51.6 \\
\text { (sec.) }\end{array}$
\end{tabular}

that the alternation of figures is orderly, " 5 complete cycles" will be $n_{\alpha}=5$ and $n_{\beta}=5$. To conform to the measure adopted by Köhler, $T$ was based on " $\beta$ " being seen as a figure five times. Six successive values of $T$ were obtained for both 10 and $60 \mathrm{sec}$. intervals. Stimulus material and other procedures were the same as those of Exp. I. Six $O$ s took part in the experiment.

Results

The average $T_{\mathrm{S}}$ for six $O_{\mathrm{s}}$ show no significant decreasing tendency for both intervals (data not shown), as was found in Exp. I.

Table 3 shows that the average $T$ for a $60 \mathrm{sec}$. interval is shorter than that for $10 \mathrm{sec}$. This result does not coincide with the $T$ obtained in Exp. I, that is, the average $T$ for a $60 \mathrm{sec}$. interval in Exp. I is little longer than that for 10 sec. (see Table 1). $T_{\varepsilon}$ for a $10 \mathrm{sec}$. 
Table 4

Total time $(T)$ (average of $4 O_{s}$ )

\begin{tabular}{|c|c|c|c|c|c|c|c|c|c|c|c|c|}
\hline Stimuli & $\begin{array}{l}\text { Order of } \\
\text { measure- } \\
\text { ment } \rightarrow\end{array}$ & 1 & 2 & 3 & 4 & 5 & 6 & 7 & 8 & 9 & 10 & AV \\
\hline \multirow{2}{*}{ A } & $10 \mathrm{sec}$. & 31.7 & 32.7 & 28.7 & 28.7 & 27.7 & 31.0 & 33.0 & 29.0 & 25.7 & 31.7 & 30.0 \\
\hline & $60 \mathrm{sec}$. & 30.3 & 20.3 & 21.3 & 21.0 & 22.3 & 21.0 & 22.0 & 26.0 & 26.3 & 19.0 & 23.0 \\
\hline \multirow{2}{*}{ B } & $10 \mathrm{sec}$. & 23.0 & 24.0 & 31.0 & 26.3 & 22.3 & 26.0 & 27.7 & 29.7 & 23.0 & 23.3 & 25.6 \\
\hline & $60 \mathrm{sec}$. & 27.7 & 17.3 & 24.3 & 23.0 & 20.3 & 22.3 & 24.3 & 20.0 & 23.7 & 20.0 & $\begin{array}{l}22.3 \\
(\mathrm{sec} .\end{array}$ \\
\hline
\end{tabular}

interval is $12.7 \mathrm{sec}$. and the $T_{c}$ for a 60 sec. is $12.5 \mathrm{sec}$, the difference being negligible.

\section{EXPERIMENT III}

\section{Method}

Exp. I and II were conducted with stimulus made of black lines drawn with India ink. In this experiment, two different stimuli were used: (A) " $\alpha$ " was black (reflectance: $2 \%$ ) and " $\beta$ " was white (reflectance: $88 \%$ ) (see Fig. 1-2); (B) " $\alpha$ " was dark gray (reflectance: $12 \%$ ) and " $\beta$ " was light gray (reflectance: $24 \%$ ). " $\alpha$ " and " $\beta$ " were both 60 . The surrounding field was middle gray (reflectance : $17 \%$ ).

In Exp. I and II the results indicated that a period of $t_{\varepsilon}$ was often followed by the response given previously, e. g., $\alpha \rightarrow \varepsilon \rightarrow \alpha$. To obtain a more orderly chain of reversals, i.e. $\alpha \rightarrow \beta \rightarrow \alpha$ etc., the new set of stimuli $A$ and $B$ were used as preliminary studies done proior to Exp. III indicated that these stimuli were more effective. *

$T$ in which 10 figures were seen was obtained successively 10 times for both 10 and $60 \mathrm{sec}$. intervals. This time $O$ was asked to take a passive attitude throughout the

* Some $O s$ frequently complained that it was hard to tell which figure was seen, though all $O_{s}$ had accuired practice in the observation of the reversals during the laboratory course in experimental psychology. They reported that stimuli $A$ and $B$ were relatively easier to observe than Fig. 1-1. observation and not try to keep any figure they saw. In Exp. I, the duration of figure may have been lengthened by $O$ 's attitude "to keep figure" $(\mathbf{1 4}, \mathbf{1 7})$. One stimulus pattern and one interval were used on a given experimental day. Four $O$ s took part in the experiment.

\section{Results}

One $O$ showed an increasing tendency of $T$ in the case of a $10 \mathrm{sec}$. interval (level of significance: $1 \%$ ), and a decreasing tendency of $T$ in the case of a $60 \mathrm{sec}$. interval (level of significance: $5 \%$ ). But as is seen in Table 4, the averaged $T$ of four $O$ s shows no significant tendency. In general, not only $T$, but also $T_{a}, T_{\beta}$ and $T_{\varepsilon}$ does not show any tendency as a function of successive observations.

The averaged $\mathcal{T}$ for each interval is compared in Table 4 in order to see the influence of interval. The average $T$ for $60 \mathrm{sec}$. is less than that for $10 \mathrm{sec}$. This tendency is found for both stimuli $\mathrm{A}$ and $\mathrm{B}$, as is shown in Table 4 .

Table 5 shows the individual results. In the case of stimulus $A$ two $O$ s indicate that $T$ for a $60 \mathrm{sec}$. interval is significantly shorter than that for 10 sec. (level of significance: $0.1 \%$ and $1 \%$ ). In the case of $\mathrm{B}$, one $O$ shows a significant difference between the $T$ for a $10 \mathrm{sec}$. interval and that for $60 \mathrm{sec}$. (level of significance: $5 \%$ ). $T_{z}$ of both was short enough to be negligible. 
Table 5

Total time $(T)$ and $S . D$. (individual data)

\begin{tabular}{|c|c|c|c|c|c|c|c|c|c|}
\hline \multicolumn{2}{|r|}{$O_{s}$} & \multicolumn{2}{|c|}{1} & \multicolumn{2}{|c|}{2} & \multicolumn{2}{|c|}{3} & \multicolumn{2}{|c|}{4} \\
\hline Stimuli & Intervals $\downarrow$ & AV. & S.D. & A.V. & S.D. & A.V. & S.D. & A.V. & S.D. \\
\hline \multirow{2}{*}{ A } & $10 \mathrm{sec}$ & 25.1 & 2.92 & 13.7 & 1.30 & 60.5 & 9.51 & 20.4 & 4.78 \\
\hline & $60 \mathrm{sec}$. & 29.7 & 7.57 & 10.5 & 0.32 & 37.2 & 10.40 & 14.3 & 3.80 \\
\hline \multirow{2}{*}{ B } & $10 \mathrm{sec}$ & 22.6 & 9.19 & 14.1 & 1.19 & 48.3 & 8.77 & 17.4 & 1.84 \\
\hline & $60 \mathrm{sec}$ & 18.9 & 6.40 & 12.4 & 0.65 & 43.2 & 11.37 & 14.8 & 3.25 \\
\hline
\end{tabular}

\section{Discussion}

Köhler found that, when continuous observation of the reversible figureground pattern such as Fig. 1-1 was repeated with $1 \mathrm{~min}$. interval, the rate of reversals gradually accelerated as the observation went on. $\mathrm{He}$ concluded that the duration of a figure would be shortened since the prolonged occurence of a figure would produce an effect which opposes the further existence of the figure.

But from the results of Exp. I, II, and III, it is difficult to find any acceleration of the rate of reversals. In this repeated observation with various intervals including the same interval as Köhler's (60 sec.), no statistically significant change in the rate of reversals could be found.

In Köhler's experiment, the measure of the rate of reversals was "the time for 5 complete cycles". In Exp. I, the measure of the rate of reversals was the total time $(T)$ in which 10 figures were seen. But owing to the inorderliness of the alternations, $T$ in Exp. I was not always " the time for 5 complete cycles". So, in Exp. II $T$ in which " $\beta$ " was seen as a figure 5 times was repeatedly obtained both with 10 and $60 \mathrm{sec}$. intervals. But no statistically significant decreasing tendency of $\mathcal{T}$ was found.

In Exp. I and II the stimulus material was the same as that used by Kohler (Fig. 1-1), but because of the difficulty of observation on the part of the observers, the stimulus material was changed to $A$ (Fig. 1-2) and B in Exp. III. Furthermore, in Exp. III $O$ was required to take a passive attitude so that the duration of a figure would not be lengthened forcibly by a voluntary attitude "to keep the figure". This time, as in Exp. I, $I$ in which 10 figures were seen was recorded successively both with 10 and $60 \mathrm{sec}$. intervals. But no statistically significant tendency of $\mathcal{T}$ was obtained.

It may be that the effect assumed by Köhler was not strong enough to accumulate progressively. Nevertheless, even if the effect did not accumulate, the duration of a figure without any interval should be shorter than or equal to that with an interval, as long as the effect existed. According to the results of Exp. I, however, the duration of $t_{\alpha}+t_{\beta}$ after each interval $(10,60$, and $120 \mathrm{sec}$.) was shorter than that without an interval $(0$ sec.). And in general the longer the interval, the shorter the duration of the first figure. This tendency is incompatible with Köhler's conclusion which presupposes that the shorter the interval the stronger the effect. Rather, it seems plausible to consider that intervals increase the rate of reversals.

This influence of the interval does not seem to be limited merely to the 
duration of the first figure. The total observation time $(T)$ for trials with intervals $(10,60 \mathrm{sec}$.) tended to be shorter than that without an interval (Exp. I). And in Exp. II and III, T for $60 \mathrm{sec}$. was shorter than that for 10 sec., though there were some minor differences between the results obtained from different stimuli.

These results are also incompatible with Köhler's findings. They seem rather to suggest that the influence of relatively long intervals is stronger than that of relatively short intervals. But, this does not mean that the influence of interval is strongest for the longest interval, as indicated by Exp. I. This assumption concerning the influence of interval needs further examination.

\section{II}

The results obtained in I suggest that intervals may increase the rate of reversals. This agrees with Obonai's result. But, in Exp. I and III, $T$ was a measure in which 10 figures were seen. This may have been an effective variable.

A difference between the results of Exp. I and II is that, while in Exp. I the $T$ for a $60 \mathrm{sec}$. interval was longer than that for $10 \mathrm{sec}$, in Exp. II the result was contrary. Exp. I and II followed the same procedures except for the length of $\mathcal{T}$, i.e., in Exp. I $\left(n_{\alpha}+n_{3}\right)$ $=10$, in Exp. II $\left(n_{\alpha}+n_{\beta}\right) \geq 10$. Hence, $\mathcal{T}$ in Exp. II was, in most cases, longer than that obtained in Exp. I. Therefore, it is possible that the influence of interval may depend on the length of $T$ or upon the amount of $\left(n_{\alpha}+n_{\hat{\beta}}\right)$. Exp. IV and $\mathrm{V}$ were conducted to test the above hypothesis.

\section{EXPERIMENT IV}

\section{Method}

Two stimulus materials, pattern $a$ and $b$ were used (see Fig. 1-3, I-4). These were circles (diameter : $5 \mathrm{~cm}$, visual angle: $2.5^{\circ}$ ) divided into six sectors. In stimulus $a, \alpha$ was $20^{\circ}$ and $\beta$ was $100^{\circ}$. In stimulus $b, \alpha$ was $40^{\circ}$ and $\beta$ was $80^{\circ}$. In both stimuli, $\%$ was made of white paper (reflectance: $88^{\circ}$, ) and $\beta$ was made of black paper (reflectance: $2 \%$ ). The reason why these stimuli were used instead of $A$ and $B$ in Exp. III was that $O$ s had reported frequently that these stimuli $a$ and $b$ were easier to observe than $A$ and $B$ of Exp. III.

$\tau$ was fixed at $120 \mathrm{sec}$. Observations were repeated 3 times both for 10 and 60 sec. intervals. One stimulus and one interval was used on a given experimental day. Other procedures were similar to Exp. III. Four Os took part in the experiment.

Results

Since $T$ was fixed, the measure of the rate of reversals, this time, was the average number of appearance $(\mathcal{N})$. $\mathcal{N}=\left(n_{a}+n_{\beta}\right) / 2$. The averaged $\mathcal{N}$ four $O \mathrm{~S}$ is shown in Table 6 . In the case of a $10 \mathrm{sec}$. interval, the decreasing tendency of $\mathcal{N}$ is evident for stimuli $a$ and $b$. The rate of reversals tends to decrease, although the observations with a $10 \mathrm{sec}$. interval are repeated only three times. All $O$ s showed the same tendency. But, when the observations are repeated with a $60 \mathrm{sec}$. interval, neither decreasing nor increasing tendency is obtained as is shown in Table 6.

As to the averaged $\mathcal{N}$ of the 3 repeated observations, while in stimulus a no difference can be observed, in stimulus $b$ the $\mathcal{N}$ for $60 \mathrm{sec}$. is greater than that for $10 \mathrm{sec}$. (see Table 6 ). This tendency can also be seen in Table 7 , in which the average duration of figure $\left(t_{\alpha}, t_{\beta}\right)$ is shown. In both $a$ and $b, t_{a}$ and $t_{\beta}$ for a $60 \mathrm{sec}$. interval are shorter than those for $10 \mathrm{sec}$, that is, the rate of reversals for $60 \mathrm{sec}$. is higher than that 
Table 6

Average number of appearance $(\mathcal{N})$

\begin{tabular}{|c|c|c|c|c|c|}
\hline $\begin{array}{l}\text { Stimulus } \\
\text { materials }\end{array}$ & Intervals $\downarrow$ & 1 & 2 & 3 & $\mathrm{AV}$ \\
\hline \multirow{2}{*}{$a$} & $10 \mathrm{sec}$ & 20.5 & 18.7 & 14.5 & 17.9 \\
\hline & $60 \mathrm{sec}$. & 19.8 & 16.3 & 17.3 & 17.8 \\
\hline \multirow{2}{*}{$b$} & $10 \mathrm{sec}$ & 20.5 & 19.5 & 17.7 & 19.2 \\
\hline & $60 \mathrm{sec}$. & 22.3 & 22.7 & 22.3 & 22.4 \\
\hline
\end{tabular}

Table 7

Average duration of figure $\left(t_{\alpha}, t_{\beta}\right)$

\begin{tabular}{c|c|ccc}
\hline $\begin{array}{c}\text { Stimulus } \\
\text { materials }\end{array}$ & Intervals $\downarrow$ & $t_{\alpha}$ & $t_{\beta}$ & $t_{\alpha}+t_{\beta}$ \\
\hline \multirow{2}{*}{$a$} & $10 \mathrm{sec}$. & 12.7 & 1.5 & 14.2 \\
& $60 \mathrm{sec}$. & 9.1 & 1.4 & 10.5 \\
\hline \multirow{2}{*}{$b$} & $10 \mathrm{sec}$. & 7.7 & 1.7 & 9.4 \\
& $60 \mathrm{sec}$. & 6.5 & 1.5 & 8.0 \\
& & & & $(\mathrm{sec})$.
\end{tabular}

for $10 \mathrm{sec}$. This suggests that, as in Exp. III, the effect with relatively long intervals is stronger than that of relatively short intervals. This may have resulted from the prolongation of $T$. At any rate it is probable that the influence of interval may have something to do with the length of $T$. This will be discussed in greater detail later.

\section{Experiment V}

\section{Method}

The stimulus material was a used in Exp. IV (Fig. 1-3). This time, the total time $(T)$ in which 4 figures were seen was obtained successively 10 times both for $10 \mathrm{sec}$. and $60 \mathrm{sec}$. intervals. That is, $\left(n_{\alpha}+n_{\beta}\right)$ was kept constant at four. Other procedures were similar to Exp. IV. Four Os took part in this experiment.

\section{Results}

One $O$ showed a significant increase of $T$ for a $10 \mathrm{sec}$. interval (level of signif- icance: $5 \%$ ) and another showed a significant decrease for $60 \mathrm{sec}$. (level of significance : $5 \%$ ).

As is seen in Table 8 , the averaged $T$ for four $O$ s does not show any significant tendency to decrease or to increase, for both intervals.

The average for 10 repeated observations indicate that the $T$ for $10 \mathrm{sec}$. is slightly shorter than that for $60 \mathrm{sec}$. Bur, as is shown in Table 9, three $O_{\mathrm{S}}$ show no statistically significant difference between the $T$ for 10 and $60 \mathrm{sec}$.

$T$ for all $O$ s is considerably shorter than the $T$ of Exp. IV (120 sec.), as seen in Table 9, though there are considerable individual differences.

Contrary to the results of pattern $a$ in Exp. IV, this result shows that the rate of reversals for $10 \mathrm{sec}$. is, if any, higher than that for $60 \mathrm{sec}$. Therefore, when $\left(n_{\alpha}+n_{\beta}\right)$ is small, the tendency observed in Exp. III and IV does not exist : that is, the relatively strong influence of the $60 \mathrm{sec}$. interval seems to cease to 
Table 8

The total time (T)

\begin{tabular}{c|ccccccccccc|cc}
\hline Intervals $\downarrow$ & 1 & 2 & 3 & 4 & 5 & 6 & 7 & 8 & 9 & 10 & AV \\
\hline 10 sec. & 31.3 & 26.7 & 23.0 & 30.3 & 36.0 & 32.7 & 28.3 & 25.0 & 28.0 & 30.7 & 29.2 \\
$60 \mathrm{sec}$. & 19.7 & 32.3 & 35.0 & 32.0 & 33.7 & 37.0 & 24.0 & 32.3 & 50.3 & 30.0 & 32.6 \\
& & & & & & & & & & & (sec.)
\end{tabular}

Toble 9

The total time $(T)$ and $S . D$. (individual data)

\begin{tabular}{|c|c|c|c|c|c|c|c|c|c|}
\hline \multirow{2}{*}{$\frac{O s}{\text { Intervals } \downarrow}$} & \multicolumn{2}{|c|}{$\mathrm{Hm}$} & \multicolumn{2}{|c|}{$\mathrm{Kt}$} & \multicolumn{3}{|c|}{$\mathrm{Sk}$} & \multicolumn{2}{|c|}{$\mathrm{Sm}$} \\
\hline & $A V$ & $S . D$ & $\mathrm{AV}$ & $S . D$ & & $\mathrm{AV}$ & $S . D$ & $\mathrm{AV}$ & S.D. \\
\hline $10 \mathrm{sec}$ & 9.5 & 2.9 & 8.0 & 2.9 & : & 73.8 & 10.8 & 25.6 & 10.6 \\
\hline $60 \mathrm{sec}$ & 8.4 & 2.3 & 10.7 & 3.2 & & 85.8 & 26.4 & 29.7 & $\begin{array}{r}7.2 \\
(\mathrm{sec} .)\end{array}$ \\
\hline
\end{tabular}

exist when $T$ is short (consequence of decreasing $n_{a}+n_{\beta}$ ).

Discussion

As the result of Exp. IV and $V$ indicates, it is difficult to observe any acceleration of the rate of reversals except for a $10 \mathrm{sec}$. interval in Exp. IV. The remarkable fact was that, when the observations for $120 \mathrm{sec}$. were repeated with $10 \mathrm{sec}$. interval, the decreasing tendency of the rate of reversals was evident. As to this decreasing tendency, some explanation other than Kohler's effect must be considered. This is beyond the scope of this experiement.

As to the influence of interval, when observations were continued for $120 \mathrm{sec}$. and were repeated 3 times, the average duration of figures for a $60 \mathrm{sec}$. interval was shorter than that for $10 \mathrm{sec}$. (Exp. IV). But, when $T$ in which 4 figures were seen was repeated 10 times, the difference between the average $T$ for 10 sec. and $60 \mathrm{sec}$. was not statistically significant (Exp. V). Therefore, it is only when considerably long observations are repeated with relatively long intervals, that a noticeable influence seems to be produced. When $\left(\mathrm{n}_{a}+\mathrm{n}_{\bar{\beta}}\right)$ is decreased, the influence seems to be weakened.

These results give a basis to suppose that the difference between the results of Exp. I and II are due to the difference between the $\mathcal{T}$ of Exp. I and II ( $T$ of Exp. I $\leq T$ of Exp. II). While the $T$ for a $60 \mathrm{sec}$. interval was shorter than that for $10 \mathrm{sec}$. in Exp. II, the $T$ for 10 sec. was the shortest in Exp. I. Probably, in Exp. I the influence of interval upon $T$ was weakened in the case of $60 \mathrm{sec}$. and ceased to be effective in the case of $120 \mathrm{sec}$.

From the result of Exp. I it is possible to infer that even if $T$ is considerably long as in Exp. IV, after a very long (at least longer than $60 \mathrm{sec}$.) interval, the rate of reversals would not be higher than that for $60 \mathrm{sec}$; in other words, the influence of intervals must not be considered to work beyond certain limitation.

On the other hand, when $T$ is considerably short as in Exp. $V$, the influence of intervals would cease to work sooner. The extent to which intervals are effective is probably dependent upon the length of $T$.

If this assumption is right, the in- 
ference is that there may be a certain interval, which is most effective in accelerating the rate of reversals. This optimum interval, however, must not be considered as being generally applicable to anyone under any condition. Various factors may be working to delimit this optimum length. $T$ itself, for instance, is a factor that determines the optimum length of intervals, if the assumption that the length of $T$ and the length of interval are interdependent is correct. This presupposes an optimum length of $\mathcal{T}$ which accelerates the rate of reversals. Then, only when an optimum $\mathcal{T}$ and interval are combined, will the rate of reversals be at a maximum.

\section{III}

Up to now this study has been on the influence of interval in the successive observations. It was suggested that intervals increased the rate of reversals. So far as this study is concerned, however, it remains to be seen what change in the rate of reversals will take place under continuous observation. The next experiment will study the course of change in the rate of reversals under continuous observations without intervals.

Köhler inserted intervals in order to overcome the difficulty that resulted when the underfined phase $\left(T_{c}\right)$ increased under long continuous observation. And the previously reported experiment showed that in some $O s, T_{\varepsilon}$ increased gradually $(\mathbf{1 4})$. These suggest that $T$ cannot be too long in studying the change of the rate of reversals.

In Exp. I repeated observations with 0 sec. interval were, in effect, prolonged continuous observations, and no significant change in the rate of reversals was observed. But, in Exp. I stimulus Fig. 1-1 was used, and so Exp. VI was conducted to study reversals under continuous observation using stimulus Fig.
$1-3 *$.

\section{EXPERIMENT VI}

\section{Method}

The stimulus material was $a$ used in Exp. IV and V. Observation time was: (I) $120 \mathrm{sec}$. (seven $O \mathrm{~s}$ ), (II) $180 \mathrm{sec}$. (four $O \mathrm{~s})$. The experiments were repeated 4 times for $2 \mathrm{~min}$. and 3 times for $3 \mathrm{~min}$. In the case of (I), two experiments were conducted in a day, between which 5 min. rest was inserted. In the case of (II), the experiments were never conducted more than once a day. Other procedures were the same as those for Exp. IV and V.

Results

As the measure of the rate of reversals, the average number of appearance $(\mathcal{N})$ within a minute was adopted. Table 10 gives the $\mathcal{N}$ for the first 1 min., the second $1 \mathrm{~min}$. and the total $\mathcal{N}$ in the case of 2 min. continuous observtion. Six $O_{\mathrm{s}}$ out of seven indicate that the $\mathcal{N}$ for the second min. is less than that for the first min. There are individual differences in $\mathcal{N}$. Total $\mathcal{N}$ ranges from 2.7 to 46.4. There are also individual differences in the change of the rate of reversals. As to the undefined phase $\left(T_{e}\right)$, four $O_{\mathrm{S}}$ showed that $T_{\mathrm{s}}$ for the second min. was longer than that for the first min., and other three $O$ s showed an opposite tendency.

Table 11 gives the $\mathcal{N}$ for the first, second and third min. under continuous observation for three minutes. Three $O$ s out of four show a decreasing tendency of $\mathcal{N}$. Average $\mathcal{N}$ for $\operatorname{six} O_{\mathrm{s}}$ in the case of two minutes continuous observation and the average $\mathrm{N}$ for three

* Oyama (12), using a stimulus similar to Fig. 1-2 (A) in this experiment, found a tendency that the rate of reversals decreased up to two minutes, then leveled off under continuous observation (10 min.). 
Table 10

Average number of appearance $(N)$ (2' continuous observation)

\begin{tabular}{|c|c|c|c|}
\hline$O_{\mathrm{s}}$ & the first $1^{\prime}$ & the second $1^{\prime}$ & total \\
\hline 1 & 12.5 & 6.5 & 19.0 \\
\hline 2 & 9.3 & 4.9 & 14.2 \\
\hline 3 & 25.2 & 21.2 & 46.4 \\
\hline 4 & 1.5 & 1.2 & 2.7 \\
\hline 5 & 4.4 & 3.0 & 7.4 \\
\hline 6 & 4.3 & 4.5 & 8.8 \\
\hline 7 & 13.3 & 10.9 & 24.2 \\
\hline
\end{tabular}

Table 11

Average mumber of appearance $(\mathcal{N})$

( $3^{\prime}$ continuous observation)

\begin{tabular}{r|rrr|r}
\hline Os & $\begin{array}{c}\text { the } \\
\text { first 1' }\end{array}$ & $\begin{array}{c}\text { the } \\
\text { second 1' }\end{array}$ & $\begin{array}{c}\text { the } \\
\text { third 1 }\end{array}$ & total \\
\hline 1 & 6.9 & 4.5 & 3.4 & 14.8 \\
2 & 7.0 & 6.0 & 5.7 & 18.7 \\
3 & 2.2 & 2.4 & 3.2 & 7.8 \\
4 & 13.2 & 11.0 & 11.2 & 35.4
\end{tabular}

Table 12

Undefined phase $\left(T_{t}\right)$

\begin{tabular}{l|ccr|r}
\hline Os & $\begin{array}{c}\text { the } \\
\text { first 1' }\end{array}$ & $\begin{array}{c}\text { the } \\
\text { second 1 }\end{array}$ & $\begin{array}{c}\text { the } \\
\text { third 1' }\end{array}$ & total \\
\hline 1 & 1.9 & 0.3 & 1.3 & 3.5 \\
2 & 3.9 & 3.9 & 9.2 & 17.0 \\
3 & 2.9 & 2.6 & 3.4 & 8.9 \\
4 & 9.3 & 8.9 & 10.8 & 29.0 \\
& & & & (sec.)
\end{tabular}

$O_{\mathrm{s}}$ in the case of three minutes are indicated in Fig. 2.

There are individual differences in $\mathcal{N}$ and also in the rate of change of $\mathcal{N}$. As is shown in Table 12, one $O$ 's $T_{\text {. }}$ increases in the third min. And a few $O$ s showed a considerable difference of $\mathcal{N}$ on different day, e. g., one $O$ 's $\mathcal{N}$ was 41 and 38 on the first day, but 57 and 57 on the second day. Another $O$ 's $\mathcal{N}$ was 87 and 86 on the first day, but 98 and 99

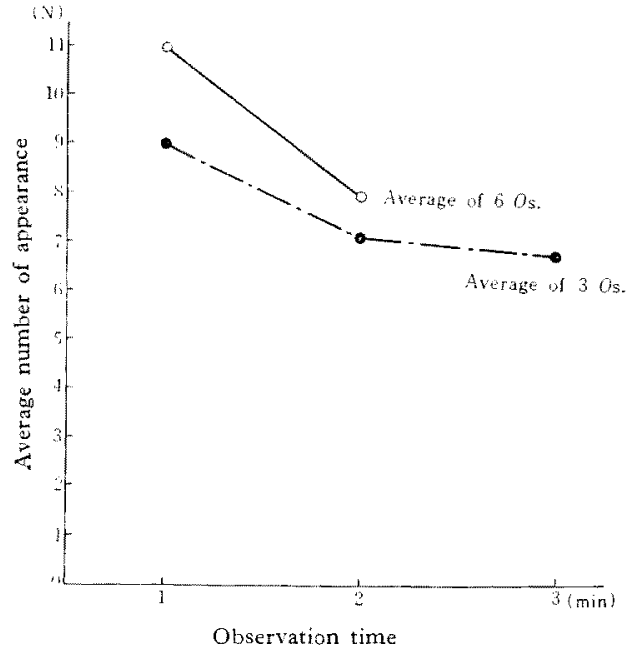

Fig. 2.

on the second day. Even on the same day, one $O$ 's $\mathcal{N}$ in the first experiment was 43 , but 34 in the second experiment.

\section{Discussion}

Setting aside one exception, when stimulus figure such as Fig. $1-3$ is used, a decreasing tendency of $\mathcal{N}$ was obtained for 2 and $3 \mathrm{~min}$. continuous observations. This course of change in the rate of reversals happens to be parallel with the result of Exp. IV, in which a 120 sec, observation time was repeated 3 times with a 10 sec. interval.

From this, it seems to suggest that considerably long continuous observation with short intervals may produce a tendency similar to that of continuous observation without interval. That is, in this case the interval seemed to be too short to increase the rate of revarsals.

Consequently, it seems to hasty to infer the course of change in the rate of reversals in general, as Köhler did, only by data drawn form the result of repeated observations with intervals. So far as these experiments are concerned, it seems that interval increases the rate of reversals. Köhler's acceleration of 
the rate of reversals might have been caused not by an accumulated effect but by a favorable combination of interval and observation time. It is plausible to consider that the combination of observation time and interval was nearly optimum in his experiment.

But above assumption is perhaps going too far, because as yet no such favorable combination has been found in this experiment. Futher study is needed to find out the reason why the acceleration of the rate of reversals, such as was obtained by Köhler, was observed in so few cases in these experiments*.

\section{Summary}

An attempt was made to determine whether the rate of figure-ground reversals is affected by successively repeated observations with fixed intervals.

Under repeated observations of the same reversible pattern as was used by Köhler with various intervals $(0,10,60$, 120 sec.) including Köhler's (60 sec.), no statistically significant trend in the rate of reversals as a function of successive observation was observed. Comparison of the rate of reversals for each interval showed that the one for 10 and $60 \mathrm{sec}$. interval tended to be higher than that for 0 sec. (i.e., without an interval), that for $10 \mathrm{sec}$. being the highest.

Examination using another pattern showed the same result, except that the rate of reversals for a $60 \mathrm{sec}$. interval was higher than that for $10 \mathrm{sec}$. This difference in the rate of reversals between a 10 and a 60 sec. interval was not effected by shortening the observation timc. When longer observations were used

* In these experiments the acceleration in the rate of reversals occurred in the following cases: one $O$ in Exp. $I(10 \mathrm{sec}$. interval), one $O$ in Exp. II $(60 \mathrm{sec}$. interval), one $O$ in Exp. III (in stimulus $B, 60$ sec. interval), one $O$ in Exp. $V$ (60 sec. interval). this difference was obtained with all the stimulus pattern including Köhler's.

The course of change in the rate of reversals under continuous observation were incompatible with Köhler's data, in that in some cases the rate of reversals tended to decrease gradually. Under longer continuous observation (120 sec.) repeated with a $10 \mathrm{sec}$. interval the same tendency was observed.

From these findings it was concluded that intervals increased the rate of reversals, and that if an optimum length of observation time and interval were combined, the influence of interval would be most effective.

\section{RefERENCES}

1. Brown, K.T. Rate of apparent change in a dynamic ambiguous figure as a function of observation-time. Amer. $\mathcal{J}$. Psychol., 1955, 68, 358-371.

2. Bruner, J. S., Postman, L., \& MostELLER, F. A note on the micasurement of reversals of perspective. Psychometrika, 1950, 15, 63-72.

3. Fisichelli, V.R. Reversible perspective in Lissajous figures; some theoretical considerations. Amer. J. Psychol., 1947, 60, 240-249.

4. Goldhamer, $H$. The influence of area, position, and brightness in the visual perception of a reversible configuration. Amer. 7. Psychol., 1934, 46, 189-206

5. GRaham, C. H. Area, color, and brightness difference in a reversible configuration. 7. gen. Psychol, 1929, 2. 470-481.

6. Guilford, J.P., \& Braly, K. W. An experimental test of McDougall's theory of extroversion-introversion. 7. $a b$ norm. soc. Psychol., 1931, 25, 382-389.

7. Harrower, M. R. Some factors determining firure-ground articulation. Brit. f. Psychol, 1936, 26, 407-424.

8. KöHLER, W. Dynamics in Psychology. 1940.

9. KöHLER, W., \& WALLACH, H. Figural after-effects. An investigation of visual processes. Proc. Amer. philos. Soc., 1944, 88, 269-359.

10. Künnapas, T. M. Experiments on figural 
dominance. 7. exp. Psychol,, 1957, 53, $31-39$.

11 OBonal, T. A study of figure-ground reversal from the stand-point of induction-theory. Jap. 7. Psychol., 1949, 19, 177-183, (In Japanese).

12. Oyana, T. Personal communication. July, 1958.

13. Oyama, T., \& Sasamoto, S. Experimental studies of figure-ground reversal (II). The effects of brightness, brightness gradient and area in the tachistoscopic presentation. Fap. 7. Psychol,, 1957, 28, (Japanese : text 18-27; English summary, 64-65).

14. Oyama, T., \& ToriI, S. Experimental studies of figure-ground reversal (I). The effects of area, voluntary control and prolonged observation in the continuous presentation. Jap. F. Psychol., 1955,
26, (Japanese text, 178-188; English summary, 217-218).

15. Oyama, T., Tori, S., \& Hamamoto, N. Experimental studies of figure-ground reversal (III). The influence of size, brightness gradient, illuminance and the number of sectors upon the rate of reversal. Jap. F. Psychol., 1957, 28, (Japanese text, 210-222; English summary, $249-250)$.

16. Philip, B. R., \& Fisichell, V. R. Effect of speed of rotation and complexity of pattern on the reversals of apparent movement in Lissajous figures. Amer. 7 . Psychol., 1945, 58, 530-539.

17. Torir, S. A study of the variables effecting figure-ground reversal. (unpublished).

(Received December 7, 1959) 